\title{
Crossmark policy page
}

The Conference Proceedings "The Herzen University Studies: Psychology in Education" uses Crossmark - a Crossref service that allows readers to see the current version of the publication.

The Crossmark icon on an article page indicates that the article has been updated.

Press the Crossmark button to see the status of a work, including any corrections, retractions or updates.

\section{Использование Crossmark}

В издании «Герценовские чтения: психологические исследования в образовании» используется сервис Crossmark, который позволяет читателю получить доступ к актуальной версии опубликованного материала.

Наличие логотипа Crossmark на странице статьи означает, что в нее были внесены изменения.

Нажмите на логотип Crossmark, чтобы получить данные о текущем статусе опубликованного документа и дополнительную информацию о нем. 